\title{
DETERMINACIÓN DE LEVETIRACETAM EN SUERO MEDIANTE HPLC-UV
}

\author{
LUZ ADRIANA SARMIENTO' \\ ${ }^{1}$ Bacterióloga PhD, Coordinadora Laboratorio de Cromatografía, Universidad Metropolitana de Barranquilla. \\ Correspondencia: lusarru@hotmail.com
}

Recibido: Septiembre 27 de 2013 Aceptado: Enero 8 de 2014

\begin{abstract}
Resumen
El Levetiracetam es un medicamento antiepiléptico derivado de la pirrolidona con un mecanismo de acción diferente a otros antiepilépticos, al unirse de forma específica a la proteína SV2A de la vesícula sináptica modulando su actividad. Diversos métodos han sido reportados para el análisis de Levetiracetam en variados fluidos biológicos, siendo la cromatografía líquida de alta precisión HPLC (de la sigla en inglés High Performance Liquid Chromatography) uno de los más utilizados. En este estudio se describe un método rápido y sencillo para la determinación de Levetiracetam en muestras de suero con extracción líquido-líquido, detección ultravioleta a $205 \mathrm{~nm}$, fase móvil isocrática y Captopril como estándar interno, el rango de detección es entre 1 y $100 \mu \mathrm{g} / \mathrm{ml}$ con precisión y exactitud del 95\% y un tiempo total de elución de 18 minutos por muestra. El método es lo suficientemente sensible, exacto, y reproductible para ser usado en estudios farmacocinéticos.
\end{abstract}

Palabras clave. HPLC, Levetiracetam, antiepilepticos, farmacocinética

\section{LEVETIRACETAM DETERMINATION IN SERUM BY HPLC-UV}

\begin{abstract}
Levetiracetam is an antiepileptic medicament derived from the pirrolidona, Its mechanism of action is different from other antiepileptic drugs, by binding specifically in the synaptic vesicle protein SV2A. Diversified methods have been brought to Levetiracetam analysis in varied biological fluids, being the High-Performance Liquid Chromatography (HPLC) one of the most used. In this study a method is described for rapid and simple Levetiracetam determination in serum samples with liquid - liquid extraction, ultraviolet detection to $205 \mathrm{~nm}$, isocratic mobile phase and Captopril as internal standard. The method is linear over the studied range of 1 and $100 \mu \mathrm{g} / \mathrm{ml}$, with $95 \%$ of precision and accuracy and total elution time to $18 \mathrm{~min}$ for a sample. This method is highly sensitive, exact and reproducible for be used in pharmacokinetic studies.
\end{abstract}

Keywords. HPLC, Levetiracetam, antiepileptic, pharmacokinetic

\section{DETERMINAÇÃO DE LEVETIRACETAM EM SORO MEDIANTE HPLC-UV}

\begin{abstract}
Resumo
A droga anti-epiléptica Levetiracetam é um derivado da pirrolidona com um mecanismo de ação diferente de outros fármacos antiepilépticos, especifica ao juntar-se com a proteína SV2A da
\end{abstract}


vesícula sináptica modulando sua atividade. Vários métodos têm sido relatados para a análise de levetiracetam em vários fluidos biológicos, a cromatografia liquida de alta precisão HPLC é um dois mais utilizados. Neste estudo relata-se um método simples e rápido para a determinação de levetiracetam em amostras de soro com a extração líquido-líquido, detecção UV a $205 \mathrm{~nm}$, fase móvel isocrática e Captopril como padrão interno, a gama de detecção situa-se entre 1 e 100 ug / $\mathrm{ml}$, com precisão e acurácia de $95 \%$ e um tempo total de eluição de 18 minutos por amostra , o método é suficientemente sensível, preciso e reprodutível para uso em estudos farmacocinéticos.

Palavras-chave: HPLC, Levetiracetam, antiepilépticos, farmacocinética.

\section{Introducción}

La epilepsia es un trastorno cerebral crónico caracterizado por alteraciones en la actividad eléctrica del cerebro que aparece a cualquier edad generalmente como episodios convulsivos. Su etiología es variada y puede estar asociada a traumatismos craneoencefálicos, lesiones estructurales del cerebro o ser de carácter idiopático, se calcula que afecta aproximadamente al $2 \%$ de la población. La mayoría de los medicamentos antiepilépticos basan su actividad principalmente en dos mecanismos: el bloqueo de los canales dependientes de sodio y de calcio a nivel interneuronal y potenciando la acción de GABA (ácido gamma-amino butírico) al inhibir las enzimas relacionadas con su degradación o bloquear su recaptación en las neuronas pre sinápticas (1).

El Levetiracetam es un medicamento antiepiléptico derivado de la pirrolidona con un mecanismo de acción diferente a otros antiepilépticos. Análisis experimentales in vivo $e$ in vitro han mostrado que el Levetiracetam se une de forma muy específica a la proteína SV2A de la vesícula sináptica modulando su actividad, al parecer afectando la fusión de las vesículas y la exocitosis de neurotransmisores, lo que se refleja en su efecto anticonvulsivo $(2,3)$. La dosis recomendada de Levetiracetam en adultos es de 500 $\mathrm{mg}$ dos veces al día y puede incrementarse hasta 1.500 $\mathrm{mg}$ dos veces al día; en niños la dosis recomendada es entre 10 y $50 \mathrm{mg} / \mathrm{kg} /$ día demostrándose en diversos estudios que es un anticonvulsivante seguro y eficaz en esta población (4). Después de su ingestión oral, cerca del 95\% se absorbe rápidamente alcanzando la máxima concentración en sangre en aproximadamente 80 minutos, menos del $10 \%$ se une a proteínas plasmáticas y cerca del $24 \%$ es metabolizado por hidrolisis enzimática del grupo acetamida, generando metabolitos sin actividad biológica que son eliminados vía renal al igual que el $66 \%$ del Levetiracetam no metabolizado. Su vida media plasmática es de 6 a 8 horas (5). Las contraindicaciones y efectos secundarios del Levetiracetam son pocos considerándose un medicamento seguro y bien tolerado (6), se debe usar con precaución en pacientes con insuficiencia renal grave debido a que esta es su vía de eliminación. En Colombia, el Levetiracetam se comercializa desde el año 2004 como molécula original con el nombre de Keppra y en presentación genérica desde el año 2010, aunque la aprobación del uso de medicamentos en Colombia está basada en estudios de bioequivalencia, es posible que no existan los suficientes estudios previos a la comercialización de algunas formas farmacéuticas de este medicamento, ya que diversos autores han reportado casos de falla terapéutica asociados a la utilización del Levetiracetam genérico (7). Es por esta razón que la creación de nuevos y sencillos métodos para estudios farmacocinéticos podrían permitir mejores análisis antes de la comercialización de algunos fármacos y el seguimiento de los mismos.

Diversos métodos han sido reportados para el análisis de Levetiracetam en variados fluidos biológicos, tales como espectrometría de masas $(8,9)$, cromatografía de gases (10) y cromatografía liquida de alta precisión HPLC (11, $12,13)$. En este estudio se ha realizado un método rápido y sencillo para la determinación de Levetiracetam en muestras de suero, basado en el método previamente reportado por Martens-Lobenhoffer con algunas modificaciones que lo hacen más sencillo, para ser empleado en estudios farmacocinéticos y se ha validado de acuerdo a los parámetros establecidos por la Oficina de las Naciones Unidas (14) y la FDA (15). El método propuesto se simplifica a una precipitación de las proteínas con ácido perclórico, seguida de la separación cromatográfica en fase reversa, utilizando fase móvil isocrática de ácido fosfórico al $5 \%$ y acetonitrilo $(90: 10 \mathrm{v} / \mathrm{v})$ con detección ultravioleta a $205 \mathrm{~nm}$ y Captopril como estándar interno. El levetiracetam cuyo nombre químico y formula son (S)- -etil-2-oxo1-pirrolidona acetamida y $\mathrm{C}_{8} \mathrm{H}_{14} \mathrm{~N}_{2} \mathrm{O}_{2}$ (figura 1), tiene un peso molecular de 170.21 gramos mol, es muy soluble en agua, parcialmente soluble en metanol y etanol e insoluble en solventes no polares como el hexano; por su parte el captopril, utilizado como estándar interno, es un antihipertensivo con formula química $\mathrm{C}_{9} \mathrm{H}_{15} \mathrm{NO}_{3} \mathrm{~S}$ (figura 1), nombre 1-(2S)-3-Mercapto-2-metilpropionil-prolina, peso 


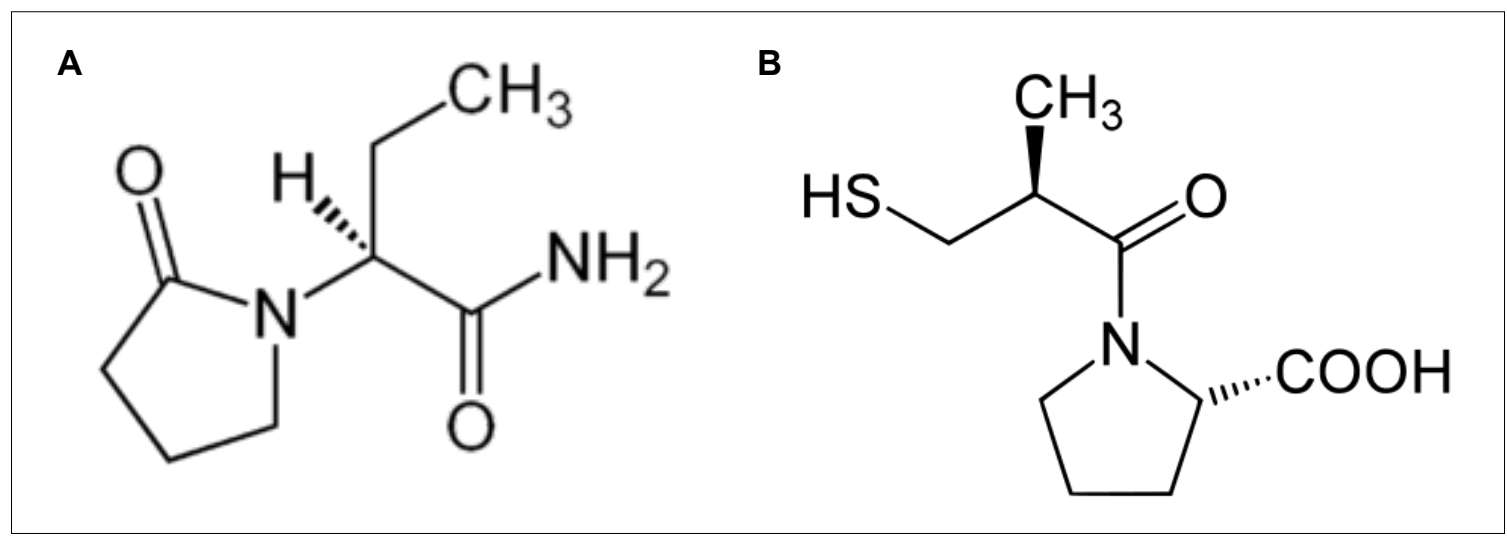

Figura 1. Estructura química de Levetiracetam (A) y Captopril (B).

molecular de 217.29 gramos mol, fácilmente soluble en agua, metanol y etanol, es estable en solución acuosa a $\mathrm{pH}$ bajo. En las condiciones cromatográficas analizadas se logra una adecuada separación de estas dos sustancias.

\section{Materiales y métodos}

Reactivos y equipos: Se utilizó estándar secundario de Levetiracetam pureza de 99,2\%; Captopril presentación comercial de $25 \mathrm{mg}$ de laboratorios tecnoquímicas como estándar interno; acetonitrilo y metanol al 99,9\% grado HPLC de J.T. Baker; ácido fosfórico $\mathrm{H}_{3} \mathrm{PO}_{4}$ al 85\%, ciclohexano al 99,9\% y ácido perclórico $70-72 \%$ fueron grado analítico de Merck. Los equipos utilizados fueron: centrífuga Mikro 200, agitador vórtex RELAX top de Heidolph, microbalanza analítica Sartorius, y congelador a $-20^{\circ} \mathrm{C}$ thermo scientific.

Sistema cromatográfico: El equipo de cromatografía utilizado fue HPLC LaChrom Elite dotado de: Bomba L2130, Inyector L2200, horno L2300 y Detector UV L2400, Columna Hypersil GOLD C8 250 x 4,6 y $5 \mu$ Part No. 25205-254630. La separación cromatográfica se realizó a $40{ }^{\circ} \mathrm{C}$ de temperatura. La fase móvil fué isocrática con flujo constante de $1,2 \mathrm{ml}$ por minuto y consistió en ácido fosfórico al 5\% y acetonitrilo en una proporción 90:10 v/v. El tiempo de elución total fué de 18 minutos por muestra.

Soluciones de trabajo: La solución Stock de Levetiracetam de $1 \mathrm{mg} / \mathrm{ml}$ fué preparada en metanol al 99,9\% grado HPLC y colocada inmediatamente a $-20{ }^{\circ} \mathrm{C}$ hasta su uso. La solución de trabajo del estándar interno Captopril a una concentración de $400 \mu \mathrm{g} / \mathrm{ml}$ fue preparada en ácido fosfórico al $5 \%$ y $50 \mu \mathrm{l}$ de esta solución colocados a cada muestra como estándar interno
Sueros control: Con firma de consentimiento informado se tomó una muestra de sangre (dos tubos sin anticoagulante) a 10 voluntarios sanos quienes manifestaron no estar tomando ningún medicamento, las muestras fueron centrifugadas a $1500 \mathrm{~g}$ durante 10 minutos, los sueros fueron extraídos y almacenados a $-20{ }^{\circ} \mathrm{C}$ hasta su uso. Cada suero de forma individual fué analizado en el HPLC para verificar la ausencia de picos interferentes con los analitos de interés y finalmente se realizó un pool de sueros a partir del cual se prepararon sueros control con concentraciones de Levetiracetam de 1, 5, 10, 20, 40, 70 y $100 \mu \mathrm{g} / \mathrm{ml} \mathrm{a}$ partir la solución de Levetiracetam de $1 \mathrm{mg} / \mathrm{ml}$.

Preparación de las muestras y curvas de calibración: $500 \mu \mathrm{l}$ de suero control fueron colocados en un tubo Eppendorf de 1,5 ml junto con $50 \mu \mathrm{l}$ de Captopril de $400 \mu \mathrm{g} / \mathrm{ml}$ como estándar interno, se agitó en vórtex 30 segundos y se adicionaron $200 \mu \mathrm{l}$ de ácido perclórico $35 \% \mathrm{v} / \mathrm{v}$ en agua bidestilada, se agitó en vórtex por 10 minutos y se centrifugó a 9000 gravedades durante 10 minutos; $200 \mu \mathrm{l}$ del sobrenadante fueron colocados en un vial para HPLC dotado con inserto para $200 \mu \mathrm{l}$ y $30 \mu \mathrm{l}$ de la muestra fueron inyectados en el HPLC. La curva de calibración se realizó procesando sueros control con concentraciones de Levetiracetam en un rango entre 1 a $100 \mu \mathrm{g} / \mathrm{ml}(1,5,10,20,40,70$ y $100 \mu \mathrm{g} / \mathrm{ml}$ ) por triplicado. Para determinar la linealidad del sistema, se estableció el valor de $\mathrm{R}^{2}$ en la curva de calibración y el coeficiente de variación entre las mediciones de una misma concentración.

Capacidad de recuperación: Soluciones de Levetiracetam de 5 y $70 \mu \mathrm{g} / \mathrm{ml}$ y sueros control con iguales concentraciones fueron analizados por triplicado para comparar los valores obtenidos en cada caso y se calculó el porcentaje de recuperación del analito. 
Especificidad: La especificidad es la capacidad del método para diferenciar el analito en presencia de otros componentes de la muestra. Diez muestras de suero provenientes de diferentes donantes fueron procesadas como muestras y analizadas para verificar la ausencia de picos en el cromatograma interferentes con el analito en cuestión. Posteriormente los cromatogramas fueron comparados con los de sueros control con concentraciones de Levetiracetam de 5 y $70 \mu \mathrm{g} / \mathrm{ml}$ adicionados de Captopril como estándar interno. En tres de las muestras de cada grupo con o sin Levetiracetam, se adicionaron $200 \mu \mathrm{l}$ de ciclohexano al tiempo con los $200 \mu \mathrm{l}$ del ácido perclórico para evaluar su efecto en la eliminación de impurezas no polares de la muestra.

Precisión y exactitud: Describe el grado de dispersión del valor obtenido respecto al valor real o conocido bajo las condiciones establecidas de análisis. Sueros control con concentraciones de Levetiracetam de 5, 20 y 70 $\mu \mathrm{g} / \mathrm{ml}$ fueron analizados por triplicado y durante dos días diferentes para evaluar la repetitividad y reproducibilidad del sistema.

Estabilidad de los analitos: La estabilidad de los analitos se evaluó por triplicado en sueros control a concentraciones de Levetiracetam de 5, 20 y $70 \mathrm{ug} / \mathrm{ml}$ y adicionados de $50 \mu \mathrm{l}$ de Captopril de $400 \mu \mathrm{g} / \mathrm{ml}$ bajo las siguientes condiciones: (i) estabilidad de congelamiento y descongelamiento: Los sueros descritos fueros someti- dos a periodos de congelación a $-20{ }^{\circ} \mathrm{C}$, descongelados a las 24 y 72 horas, procesados, evaluados y los resultados comparados con sueros sin congelar. (ii) estabilidad de los sueros control a temperatura ambiente: Los sueros control fueron analizados después de ser procesados y permanecer 24 y 72 horas a temperatura ambiente en el auto muestreador. Y (iii) estabilidad de las soluciones: Soluciones de Levetiracetam de $20 \mu \mathrm{g} / \mathrm{ml}$ y sueros control de igual concentración fueron adicionadas de estándar interno y procesadas como una muestra, posteriormente fueron analizadas después de permanecer 15 y 22 horas a temperatura ambiente en el auto muestreador

\section{Resultados}

Se adaptó, estandarizó y validó un método analítico mediante HPLC-UV para la determinación de Levetiracetam en suero humano con estándar interno Captopril, del cual se resumen las condiciones instrumentales en la tabla 1

Los análisis de especificidad demostraron que no existe ningún pico en el tiempo de retención de Levetiracetam ni de Captopril cuando se analizaron separadamente diez muestras de suero solo, en comparación a muestras que contenían los analitos (figura 2). No se observaron diferencias significativas respecto a la eliminación de impurezas en la muestra en los cromatogramas de las muestras adicionadas con ciclohexano frente a las tratadas solo con

Tabla 1. Condiciones instrumentales para la determinación de Levetiracetam en suero mediante HPLC-UV.

\begin{tabular}{|l|l|}
\hline \multicolumn{1}{|c|}{ Parámetros instrumentales } & \multicolumn{2}{c|}{ Condiciones } \\
\hline Fase móvil & Acido fosfórico 0,5\%: acetonitrilo (90:10) \\
\hline Modo de elución & Isocrático \\
\hline Longitud de onda & $205 \mathrm{~nm}$ \\
\hline Columna & Fase reversa C8 $5 \mu \mathrm{m}, 250 \times 4,6 \mathrm{~mm}$ \\
\hline Temperatura columna & $40^{\circ} \mathrm{C}$ \\
\hline Temperatura del auto muestreador & Ambiente \\
\hline Flujo de fase móvil & $1,2 \mathrm{ml} / \mathrm{min}$ \\
\hline Volumen de inyección & $30 \mu \mathrm{L}$ \\
\hline Modo de cuantificación & Estándar interno y curva de calibración \\
\hline Modo de cualificación & Tiempo de retención \\
\hline Unidades de concentración & $\mu \mathrm{g} / \mathrm{mL}$ \\
\hline Tiempo de retención Levetiracetam & $5,2 \mathrm{~min}$ \\
\hline Tiempo de retención Captopril & $14,25 \mathrm{~min}$ \\
\hline Tiempo de corrida & $18 \mathrm{~min}$ \\
\hline
\end{tabular}



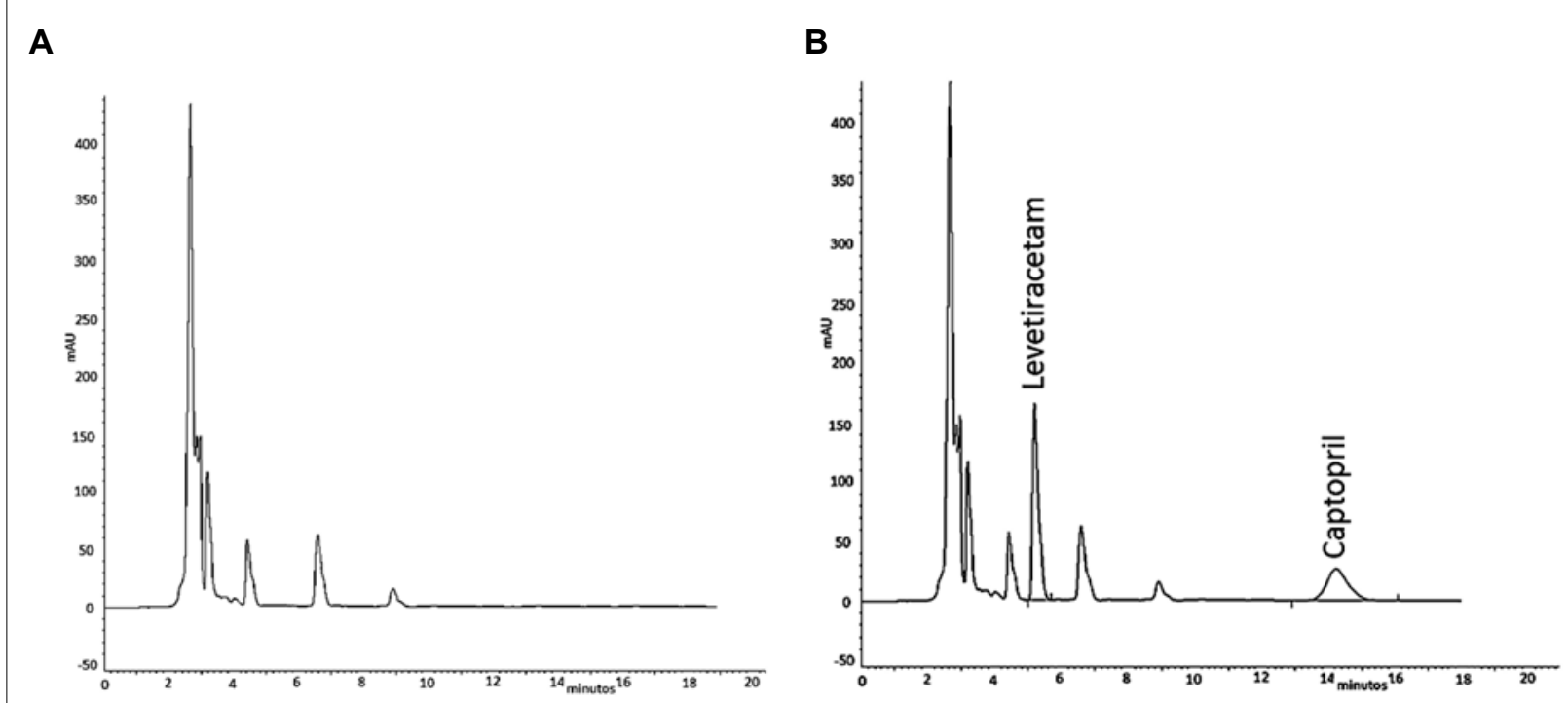

Figura 2. A. Cromatográma obtenido con un suero solo; B. Cromatográma de Levetiracetam 70 ug/ml (5,2 min) y Captopril estándar interno $(14,25 \mathrm{~min})$.

ácido perclórico, obteniéndose cromatográmas con un patrón de picos iguales a los observados en la figura 2 para ambos casos, cuando la muestra contenía o no el principio activo. Los tiempos de retención para estas moléculas fueron 5,2 minutos para Levetiracetam y 14,25 minutos para Captopril.

Los resultados del modelo lineal para la elaboración de la curva de calibración de Levetiracetam indican la correlación existente entre la concentración y la medida del área de los picos obtenidas en muestras de suero con el analito, se obtuvo un $\mathrm{R}^{2}$ estadístico de 0,993 y en ningún caso el coeficiente de variación entre las áreas obtenidas en mediciones de sueros con la misma concentración fue superior a $1 \%$ lo cual indica que hay muy poca dispersión entre las mediciones de una misma concentración (tabla 2).

La eficiencia de la extracción se calculó mediante la comparación de las relaciones de área de las muestras extraídas y los estándares no extraídos observándose que a una concentración de Levetiracetam de $5 \mu \mathrm{g} / \mathrm{ml}$ la recuperación es de 99,11\% y a concentración de $70 \mu \mathrm{g} / \mathrm{ml}$ es de $96,04 \%$, el coeficiente de variación de las réplicas en cada caso es inferior a $1 \%$ (tabla 3 ).

La precisión de las mediciones en las concentraciones de Levetiracetam 5, 20 y 70 siempre tuvo un coeficiente de variación inferior a $1 \%$, respecto a la exactitud el porcentaje de error de las mediciones a las concentraciones analizadas nunca fue superior a 5\% (tabla 4)
Los análisis de estabilidad muestran que Levetiracetam en una muestra de suero es estable a la congelación y descongelación en los periodos analizados, cuando soluciones de Levetiracetam fueron dejadas en el auto muestreador por más de 20 horas se observó que sufren una disminución en la concentración de la muestra inferior al $5 \%$ por esta razón las muestras nunca fueron dejadas por un tiempo superior a veinte horas en el auto muestreador después de su preparación.

\section{Discusión}

En el mundo hay aproximadamente 50 millones de personas con epilepsia y cerca del $80 \%$ son de regiones en desarrollo de acuerdo a las cifras de la Organización Mundial de la Salud. En Colombia la epilepsia tiene una prevalencia de 11,3 por cada 1000 habitantes (16) y aunque existen diversos medicamentos para su tratamiento aproximadamente en el $30 \%$ de los casos estos no logran la efectividad necesaria persistiendo las crisis epilépticas y presentándose la denominada epilepsia refractaria, que es debida, entre otros a factores farmacocinéticos, farmacodinámicos o de resistencia farmacológica en dichos pacientes (17). Resulta entonces de gran importancia el desarrollo e implementación de métodos analíticos que permitan el monitoreo constante de los medicamentos antiepilépticos en muestras biológicas así como su implementación en el estudio para el desarrollo de nuevos me- 
Tabla 2. Resultados del estudio de linealidad.

\begin{tabular}{|c|c|c|c|c|}
\hline $\begin{array}{c}\text { Concentración } \\
\text { Levetiracetam } \mu \mathrm{g} / \mathrm{ml}\end{array}$ & Área del pico & Promedio & $\begin{array}{c}\text { Desviación } \\
\text { estándar }\end{array}$ & $\begin{array}{c}\text { Coeficiente de } \\
\text { variación } \%\end{array}$ \\
\hline \multirow{3}{*}{100} & 11407929 & \multirow{3}{*}{11355714} & \multirow{3}{*}{46485,72} & \multirow{3}{*}{0,41} \\
\hline & 11340384 & & & \\
\hline & 11318830 & & & \\
\hline \multirow{3}{*}{70} & 8132319 & \multirow{3}{*}{8101394} & \multirow{3}{*}{31904,42} & \multirow{3}{*}{0,39} \\
\hline & 8103271 & & & \\
\hline & 8068593 & & & \\
\hline \multirow{3}{*}{40} & 4962199 & \multirow{3}{*}{4909443} & \multirow{3}{*}{46198,04} & \multirow{3}{*}{0,94} \\
\hline & 4889913 & & & \\
\hline & 4876218 & & & \\
\hline \multirow{3}{*}{20} & 2733558 & \multirow{3}{*}{2740095} & \multirow{3}{*}{8013,59} & \multirow{3}{*}{0,29} \\
\hline & 2749035 & & & \\
\hline & 2737691 & & & \\
\hline \multirow{3}{*}{10} & 1546665 & \multirow{3}{*}{1537169} & \multirow{3}{*}{9477,06} & \multirow{3}{*}{0,62} \\
\hline & 1537130 & & & \\
\hline & 1527711 & & & \\
\hline \multirow{3}{*}{5} & 965812 & \multirow{3}{*}{967239} & \multirow{3}{*}{2366,49} & \multirow{3}{*}{0,24} \\
\hline & 969971 & & & \\
\hline & 965935 & & & \\
\hline \multirow{3}{*}{1} & 403991 & \multirow{3}{*}{403260} & \multirow{3}{*}{2305,69} & \multirow{3}{*}{0,57} \\
\hline & 400677 & & & \\
\hline & 405111 & & & \\
\hline
\end{tabular}

Tabla 3. Capacidad de recuperación de Levetiracetam en el proceso de extracción del suero.

\begin{tabular}{|c|c|c|c|c|c|}
\hline Concentración & $\begin{array}{l}\text { Levetiracetam } \\
\text { en solución }\end{array}$ & $\begin{array}{c}\text { Suero con } \\
\text { Levetiracetam }\end{array}$ & $\begin{array}{c}\% \\
\text { recuperación }\end{array}$ & Promedio & $\begin{array}{c}\text { Coeficiente de } \\
\text { variación \% }\end{array}$ \\
\hline \multirow{3}{*}{70} & 8404034 & 8132319 & 96,77 & \multirow{3}{*}{96,04} & \multirow{3}{*}{0,77} \\
\hline & 8435048 & 8103271 & 96,07 & & \\
\hline & 8468250 & 8068593 & 95,28 & & \\
\hline \multirow{3}{*}{5} & 979726 & 965812 & 98,58 & \multirow{3}{*}{99,11} & \multirow{3}{*}{0,77} \\
\hline & 970179 & 969971 & 99,98 & & \\
\hline & 978003 & 965935 & 98,77 & & \\
\hline
\end{tabular}

dicamentos y el mayor conocimiento de los ya existentes. El Levetiracetam es un fármaco antiepiléptico considerado de nueva generación ya que su mecanismo de acción difiere de los demás antiepilépticos de uso común. Algunos autores consideran que el el Levetiracetam puede ser el medicamento de elección en pacientes con epilepsia refractaria y diferentes estudios así lo demuestran $(18,19)$.

En este trabajo se validó un método sencillo y rápido para la determinación de Levetiracetam en muestras de suero mediante HPLC con detección ultravioleta a $205 \mathrm{~nm}$. Otros autores han reportado previamente métodos para la determinación de Levetiracetam en suero utilizando
HPLC- UV, Zufia y colaboradores en el 2010 describen un método con extracción en fase solida utilizando las columnas OASIS HLB (20); Contin y colaboradores en 2008 (12) hacen una precipitación de las proteínas séricas con metanol y eliminan parte de los lípidos interferentes por centrifugación de la muestra a 4 C; Martens-Lobenhoffer en el 2004 (11) realiza una precipitación proteica con ácido perclórico adicionando ciclohexano para eliminar las interferencias no polares en la muestra y hace la separación cromatográfica con un gradiente de acetonitrilo y ácido fosfórico, siendo este último método en el que se basa el aquí reportado con las modificaciones que se describen a continuación y que lo hacen más sencillo: Se suprimió 
Tabla 4. Resultados de la determinación de Levetiracetam en diferentes días.

\begin{tabular}{|c|c|c|c|c|c|}
\hline$\mu \mathrm{g} / \mathbf{m l}$ & $\begin{array}{c}\text { Suero con } \\
\text { Levetiracetam }\end{array}$ & Área del pico & $\begin{array}{c}\text { Levetiracetam } \\
\qquad \mu \mathrm{g} / \mathrm{ml}\end{array}$ & $\begin{array}{c}\text { Coeficiente de } \\
\text { variación \% }\end{array}$ & $\begin{array}{c}\text { Error } \\
\text { relativo \% }\end{array}$ \\
\hline \multirow{6}{*}{70} & \multirow{3}{*}{ Día 1} & 8132319 & 70,16 & \multirow{6}{*}{0,56} & \multirow{6}{*}{0,35} \\
\hline & & 8103271 & 69,90 & & \\
\hline & & 8068593 & 69,58 & & \\
\hline & \multirow{3}{*}{ Día 5} & 8198758 & 70,77 & & \\
\hline & & 8117023 & 70,02 & & \\
\hline & & 8113462 & 69,99 & & \\
\hline \multirow{6}{*}{20} & \multirow{3}{*}{ Día 1} & 2733558 & 20,89 & \multirow{6}{*}{0,70} & \multirow{6}{*}{4,19} \\
\hline & & 2749035 & 21,03 & & \\
\hline & & 2737691 & 20,93 & & \\
\hline & \multirow{3}{*}{ Día 5} & 2705705 & 20,63 & & \\
\hline & & 2726859 & 20,83 & & \\
\hline & & 2713191 & 20,70 & & \\
\hline \multirow{6}{*}{5,0} & \multirow{3}{*}{ Día 1} & 965812 & 4,75 & \multirow{6}{*}{0,43} & \multirow{6}{*}{4,39} \\
\hline & & 969971 & 4,79 & & \\
\hline & & 965935 & 4,75 & & \\
\hline & \multirow{3}{*}{ Día 5} & 969890 & 4,79 & & \\
\hline & & 971015 & 4,80 & & \\
\hline & & 969677 & 4,79 & & \\
\hline
\end{tabular}

el uso de ciclohexano al evidenciarse en las pruebas realizadas que no implicaba reducciones significativas de las impurezas polares de la muestra y que las presentes no interferían con la especificidad de método para el analito de interés, se utilizó fase móvil isocrática de ácido fosfórico al 5\% y acetonitrilo 90:10 v/v obteniéndose un tiempo de retención para el Levetiracetam de 5,2 minutos, similar al obtenido por Martens-Lobenhoffer que fue de 6,8 minutos utilizando un gradiente de los mismos solventes y se implementó el uso de Captopril como estándar interno al considerarlo un parámetro importante para garantizar el control de posibles errores en la manipulación de la muestra y de los volúmenes de inyección en el equipo. Se evidencio además que la separación cromatográfica de Levetiracetam y Captopril en las condiciones descritas, se realiza eficientemente en una columna de fase reversa convencional como la C8 utilizada en este estudio y que la retención del Levetiracertam es similar a la lograda en una columna de Carbón Poroso Grafitizado (PGC) como la HyperCarb utilizada en el método de referencia. Aunque el Levetiracetam no se metaboliza de forma importante en humanos, el $24 \%$ del medicamento adsorbido sufre una hidrolisis enzimática del grupo acetamída dando origen al principal metabólito ucb L057 sin actividad biológica, el cual es difícilmente separado por métodos cromato- gráficos de fase reversa, interferencia que se presenta en muchos de los métodos analíticos reportados incluido el de este trabajo, este inconveniente puede ser superado combinando a la técnica HPLC otra tecnología como la espectrometría de masas que permitiría una clara diferenciación de estas dos moléculas (21).

\section{Conclusiones}

El método analítico descrito y validado para la determinación de Levetiracetam en sangre utilizando como estándar interno Captopril mediante la técnica HPLC-UV es específico para el principio activo de interés, tiene la exactitud, precisión, linealidad y reproductividad adecuadas para dicho análisis, por lo tanto se puede utilizar en estudios de farmacocinética, biodisponibilidad y bioequivalencia para productos que contengan Levetiracetam como principio activo.

\section{Agradecimientos}

Al laboratorio de Toxicología Vargas-Melo de la Ciudad de Bogotá, por el aporte de algunos de los materiales y reactivos necesarios para la elaboración de este trabajo. 


\section{Bibliografía}

1. Czapinski P, Blaszczyk B, Stanislaw J. Czuczwar. Mechanisms of Action of Antiepileptic Drugs. Current Topics in Medicinal Chemistry. 2005; 5: 3-14.

2. Lynch B, Lambeng N, Nocka K, Kensel-Hammes P, Bajjalieh $\mathrm{S}$, Matagne A, Fuks B. The synaptic vesicle protein SV2A is the binding site for the antiepileptic drug levetiracetam. PNAS. 2004; 101 (26): 9861-9866.

3. Meehan A, Yang X, McAdams B, Yuan L, Rothman S. A new mechanism for antiepileptic drug action: vesicular entry may mediate the effects of levetiracetam. AJP - JN Physiol . 2011; 106 (3): 1227-1239.

4. Giroux PC, Salas-Prato M, Théorêt Y, Carmant L. Levetiracetam in children with refractory epilepsy: lack of correlation between plasma concentration and efficacy. Seizure. 2009; 18(8):559-63.

5. Patsalos PN. Clinical pharmacokinetics of levetiracetam. Clin Pharmacokinet. 2004; 43(11):707-724.

6. Rupprecht S, Franke K, Fitzek S, Witte O W, Hagemann G Levetiracetam as a treatment option in non-convulsive status epilepticus. Epilepsy Research. 2007; 73(3): 238-244.

7. Granados A. Fallo terapéutico y eventos adversos asociados al uso de Levetiracetam genérico: un reporte de 4 casos. Acta Neurol Colomb. 2011; .27 (2):129-133.

8. Austgulen Westin A, Reimers A, Helde G, Nakken K. O, Brodtkorb E. Serum concentration/dose ratio of levetiracetam before, during and after pregnancy. Seizure. 2008;17: 192-198.

9. Guo T, Oswald L. M, Rao Mendu D, Soldin S. J. Determination of levetiracetam in human plasma/serum/saliva by liquid chromatography-electrospray tandem mass spectrometry.Clinica Chimica Acta. 2007; 375 (1-2): 115-118.

10. Vermeij T.A, Edelbroek P.M. High-performance liquid chromatographic and megabore gas-liquid chromatographic determination of levetiracetam (ucb L059) in human serum after solid-phase extraction. Journal of Chromatography B: Biomedical Sciences and Applications. 1994; 662. (1): 134-139.

11. Martens-Lobenhoffer, Bode-Boger M. S. Determination of levetiracetam in human plasma with minimal sample pretreatment . Journal of Chromatography B. 2005; 819:197-200
12. Contin M, Mohamed S, Albani F, Riva R, Baruzzi A. Simple and validatedHPLC-UVanalysis of levetiracetam in deproteinizedplasma of patients with epilepsy. Journal of Chromatography B. 2008; 873 (1- 15): 129-132

13. Mohammadi B, Majnooni M, Afnanzade N, Jalili R, Bahrami G. Simple and rapid ultra-high performance liquid chromatographic (UHPLC) method for the determination of levetiracetam in human serum: Application to a bioequivalence study. African Journal of Pharmacy and Pharmacology. 2012; 6(27): 2017-2022.

14. Oficina de las Naciones Unidas contra la Droga y el Delito. Directrices para la validación de métodos analíticos y la calibración del equipo utilizado para el análisis de drogas ilícitas en materiales incautados y especímenes biológicos. 2010. Disponible en: http://www.unodc.org/documents/scientific/Validation_ Manual_STNAR41_Ebook_S.pdf

15. U.S. Department of Health and Human Services Food and Drug Administration, Center for Drug Evaluation and Research (CDER), Center for Veterinary Medicine (CVM). Guidance for Industry Bioanalytical Method Validation. 2001. Disponible en: http:// www.fda.gov/downloads/Drugs/.../Guidances/ucm070107.pdf

16. Vélez A, Eslava-Cobos J. Epilepsy in Colombia: epidemiologic profile and classification of epileptic seizures and syndromes. Epilepsia. 2006; 47(1):193-201.

17. Torres Zambrano M, Castillo Támara E, Camargo Ballestas J. M. Resistencia farmacológica en epilepsia. Acta Neurológica Colombiana. 2007;23 (4): 279-285.

18. Grant R., Shorvon SD. Efficacy and tolerability of 1000-4000 mg per day of levetiracetam as add-on therapy in patients with refractory epilepsy. Epilepsy research. 2000; 42(2-3):89-95.

19. Grosso S, Franzoni E, Coppola G, Iannetti P, Verrotti A, Cordelli D.M, et al. Efficacy and safety of levetiracetam: An add-on trial in children with refractorye pilepsy Seizure. 2005; 14 (4): 248-253.

20. Zufía L, Aldaz A, Ibáñez N, Giráldez J, Viteri C. LC method for therapeutic drug monitoring of levetiracetam: Evaluation of the assay performance and validation of its application in the routine area. Clinical Biochemistry. 2010; 43: 473-482.

21. Rao Mendu D, Soldin S. Simultaneous determination of Levetiracetam and its acid metabolite (ucb L057) in serum/ plasma by liquid chromatography tandem mass spectrometry. Clinical Biochemistry. 2010; 43 (4-5): 485-489 